\title{
Deliver us from evil: The role of faith and family in coping with stress among African migrants in Australia
}

\author{
Irene Ikafa ${ }^{1}$ and Dieu Hack-Polay ${ }^{2}$
}

\begin{abstract}
The paper examines stressors affecting involuntary and voluntary African migrants in Australia and how they cope with stress. Using semi-structured interviews, the paper examines the experiences of 30 African migrants in Australia. Most participants used a diversity of strategies including the reliance of divine intervention and family -usually constructed by alliance rather than kinship -to cope with stress. The key contribution of the paper is to go beyond traditional integration strategies to highlight the significance of faith and family as remedies to 'deliver' the migrants from the obstacles to effective resettlement and psychological healing.
\end{abstract}

Keywords: African migrants; stress; faith; family; resettlement; coping strategies.

1. Lecturer in Nursing, Faculty of Medicine and Health, University of New England, Australia

2. Associate Professor, University of Lincoln

Address for corrrespondence: iikafa@une.edu.au,DHackpolay@lincoln.ac.uk

Date of first (online) publication: 18th December 2019 


\section{Introduction}

The debate surrounding migrants has been the subject of debate globally for decades. With the inflow of hundreds of thousands of migrants in the past three decades in particular, questions have arisen about the West's capacity to absorb the new migrants and the impact of such influx on Western culture, race relations, demographics and the economy (OECD, 2015). There is little consensus as to the real impact of these recent migratory movements. The Syrian crisis which has brought over a million refugees to Europe in 2015 (The Telegraph, 2015; UNHCR, 2015), has exacerbated the debate. Some in the media and political arenas contend that opening the West's borders to the entry of thousands of new residents has detrimental effects in that migrants are a cost and burden to the host nations. However, other authors question the validity of such arguments (Ostrand, 2015; Hack-Polay, 2000, 2006; Refugee Council, 2002). Migrating to countries like Australia can be beneficial for African migrants but stressors associated with resettlement may be substantial and could have a profound effect on their mental health and the well-being of migrants. Previous studies have established that African migrants often experience stress related to separation, acculturation, multiple losses, and isolation (Muli et al, 2009). Stress can result in some migrants constantly thinking about their homeland, not sleeping well, refusing to eat food and feeling weak and anxious (Ward, 2000). Homesickness has also been identified among migrant workers and expatriates (Hack-Polay, 2012).There is convergence of view in the literature that the host country can be a tough endeavour for migrants, often difficult to penetrate, to move through it and to survive it (Maloutas, 2012; Pessar, 2005). This research aims to examine critical strategies developed by SubSaharan migrants in Australia to combat stress deriving from displacement and socialization into a new societal nomenclature. We set out to examine whether beyond retraining and finding employment, there are other psychological and spiritual strategies that the migrants deploy to cope with stress in exile.

\section{Literature review}

It is well documented in the literature that migrants experience a significant amount of stress as a result of role and identity discontinuity (Von Mende, 2008). Migrants are confronted with many factors that contribute to the stress that they experience. An issue well reported in the literature that causes migrant to be stressed and disadvantaged is the lack of recognition of their prior learning or qualifications. As a result, many migrant take up jobs which are lower than the positions they once held in the homeland (Hack-Polay, 2008; Green, 2007). Sectors such as hospitality and retail absorb significant numbers of migrants but they equally offer largely 
jobs that represent underemployment when compared with the skills that migrants harbour (Hack-Polay \& Igwe, 2018; Hack-Polay \& Mendy, 2017; Barrett et al., 2006). The lowering of their professional status is a key stressor and source of dislocation in the host country.

Some research caution against patronizing and pathologizing the migrant status. In fact many writings perceive the migrants as passive victims, thus ignoring their capacity via agency which help the migrants overcome the obstacles that they have to surmount (Syrett \& Lyons, 2007). Leaving cultural spaces in which one has deeply rooted connections is often credited with dramatic socio-economic and psychological effects. Migrants use various strategies to adapt to life in the host country and make sense of new social realities. The article examines the significance of marriage and the recreation of the family as a socialisation strategy among others.

Resettling migrants in new collectivities has allied complications and this line of argument has commanded much analyses. A critical aspect of this debate contends that adaptation is one of the challenges migrant face. The behaviour and mental health of refugees can be profoundly affected by such issues and climax in intense stress. Hack-Polay (2010) believes that seven key elements cause and exacerbate stress levels in migrants. Such factors include separation, and trauma resulting from separation but also from dislocation and social isolation in the host country as well as status inconsistency, and acculturation stress (Hack-Polay, 2010; Ghorashi 2005; Lin 1986). These factors help to understand the multifaceted nature of the migrant experience.

A critical factor associated with the resettlement process is acculturative stress. This emanates from the dual and overlapping process of grieving and at the same time navigating the socialization process. Acculturative stress is the disruption in social ties following the encounter with a different culture, usually more dominant than once original culture (Berry, 1970). It is characterized by psychosocial anxiety which impair the usual behavior of individuals and their ability to perform normal social roles. Fletcher (1984) argues that stress can damage the life expectancy of those suffering from the issue, denoting the dangers of protracted periods of stress. Many authors (Zhong et al., 2016; Kobasa, 1979; Smart and Smart, 1995) support this assumption, arguing that acculturative stress can 'precipitate' the degradation of physical health. In a recent study of Filipino migrants in Australia, Maneze et al. (2014) found evidence that acculturative stress had key implications for health promotion, pointing to the degree to which the level of stress affect migrants' diet, lifestyles which led them to develop various physical health problems.

The reconstruction of a familiar social context needs to take account of culture because acculturation has often been another big problem for displaced people and refugees. Kovacev and Shute (2004) argue that living in a different culture has psychological and social impacts on displaced people, both at individual and group levels. Most specialists in the field agree that these impacts are far reaching for international migrants. Lin (1986) argues that many migrants struggle to adapt 
to complex socio-cultural realities that are not only alien in many cases, but also critically dynamic. This is exacerbated where there is a significant cultural distance between the migrants and their new society. The adaptation difficulties for migrants is well-documented (see Wagner \& Obermiller, 2004; Rumbaut \& Rumbaut, 1976). These difficulties are so acute in some cases that, given the choice many migrants will sit out the process according to Hack-Polay (2008) and Berry (1986) and confine themselves to the ethnic enclave, the purpose of which is to remain close to their own culture and identity. The problem of identity is part of the struggle faced by refugees (MacFadyean, 2001), many of whom feel a sense of belonging in the host society in time, while their self-proclaimed sense of belonging may be denied by the dominant society.

Through competence in the host country culture, migrant can aspire to be part of their new collectivity. The level of socialisation and inclusion differs sizably depending on the social and cultural baggage and location in the host country. For example, those with strong prior academic backgrounds and those escaping with the family ties and relevant ethnic networks, thus social networks, can often display an adaptation advantage.

\section{Migrant social networks}

Social networks represent social capital that assist the migrants in their attempt to root themselves in the new society. Migrant social networks are predominantly in the realm of ethnic networks and enclaves. Such networks help migrants maintain some familiar norms and values which provide a degree of psychology safety. These networks play an essential role in migrant integration. As Omi and Winant (1986) values and norms help migrants succeed in the integration process. These authors argue that migrant networks fulfill various types:

- affirm identity

- remain connected to their roots

- preserve their heritage

However, migrant networks have been found to be also vital in alleviating acculturative stress and other psychological effect of migration. However, the role of migrant social networks could be contradictory (Hack-Polay, 2008). Whilst they can soothe the transition homeland citizens to migrants in an alien socio-cultural and physical sphere, migrant networks could present a degree of dysfunctionality and become barriers that retain migrants in situation where there are indecisive about whether to strengthen efforts to integrate or to fashion separate lives in the migrant and ethnic enclave (Stein 1986). 


\section{Stress impacting on African migrants}

Regardless of the level of preparation, migration to a new country and new culture, whether voluntary or otherwise, is a complex process that is likely to result in a degree of culture shock which can be stressful. African migrants may encounter stress associated with loss of homeland, family, friends, and social networks. In case of involuntary migrants, there may also be loss of the lives of family members, friends or loss of all possessions. Multiple losses was established as a source of stress for African migrants in Australia who professed they had lost almost everything (Ogunsiji et al., 2012). Another stressor affecting involuntary African migrants is separation from family members. Sudanese refugees in Australia experienced constant stress because of separation from their family and friends who often remain in refugee camps and war zones (Savic et al., 2013). A major stressor impacting on African migrants is racial discrimination. A study in Australia found that African refugees because their dark skin colour, experienced more discrimination compared to other refugees with lighter skin (Colic-Peisker, 2009). High levels of discrimination was also found among African refugees in the Australian labour market and everyday life (Fozdar \& Torezani, 2008; Hacock, 2017). Other stressors may emergy during the course of resettlement of migrants. Somali refugees were stressed because of cultural differences, parenting issues, gender and role reversal (Omar, 2003). Somali female refugees in Australia also had challenges in their ability to use social networks and produce social capital during their resettlement process in Australia (McMichael \& Manderson, 2004).

Studies in other countries have shown that culture shock can also cause stress among migrants. Most Sudanese women in Baird's study experienced culture shock because they found the culture in the US different. Culture shock can be terrifying and stressful, particularly for refugees who have been forced out of their country and have never travelled outside their country (Baird, 2012).

Gender and role reversal can also create stress within African families due to disparity between men and women. The issue of role reversal is a major factor affecting relationships within the families of African migrants, which can result in family violence, breakdown and divorce (Abur 2018; Abur \& Spaaij 2016; Heger Boyle \& Ali, 2010; Kuyini \& Kivunja 2018). In African cultures, the roles of men, women and children are well defined, and each member of the family functions within these boundaries. Traditionally, African men are the head of the family and are responsible for providing material and financial support for their families. The major challenge for many African men is acceptance of the differing and complementary roles of women in mainstream Australian society (Ahmed, 2006). 


\section{Coping strategies used by African migrants}

People cope in different ways when faced with stressful situations. Refugees from Southern Sudanese refugees in Australia used coping strategies, such as using inner resources, social support networks and focusing on hope and their future (Khawaja et al, 2008). McMichael and Manderson (2004) also recognized that African refugees in Australia who use social networks accessed more social and material support and suffered less sadness and distress. Refugees endure severe difficulties by holding aspirations for a better future in Australia (Peisker \& Tilbury, 2003).

As found by studies conducted outside Australia, most African migrants cope with stress by getting support from family and connections with their ethnic cultural group to retain a degree of ethnic identity and belonging (Phinney et al, 2001). Women, adolescents and single people benefit from extended family support, which helps them cope with the resettlement stressors (Taylor et al, 2013). Social support is an external coping resource that includes the practical help, guidance and reassurance from a range of sources in time of need (Smith, 2004).

Consequently, unaccompanied young refugees from southern Sudan used coping strategies such as helping each other, restraint and diversion (Goodman, 2004). Prayer is also an important coping strategy used by African migrants (Ager \& Strang, 2008). The primary source of coping among Somali and Ethiopian refugees is praying to relieve their sadness in hopeless situations (Halcón et al., 2004). Prayer is an effective coping strategy to deal with past trauma (Goodman, 2004, Khawaja et al., 2008). While some studies already exist about African migrants in Australia, they appear to be limited to refugees only. This is a significant gap, hence, our study aimed to examine the major stressors impacting on the mental health and wellbeing of both involuntary and voluntary African migrants. It also aimed to explore the coping strategies they use to aid their resettlement process in Australia.

\section{Method}

The study examined the major stressors impacting on the mental health of both involuntary and voluntary African migrants and how they cope with stress. The study used exploratory interpretive qualitative research design, using in-depth faceto-face interviews to allow participants to express their experiences and feelings that were pertinent to their personal circumstances. We sought to investigate the resettlement experiences of African migrants in Australia. It also aimed to examine the status of the mental health of African migrants and how they cope with stress, and to evaluate the available migrant support services. A sample of 30 participants were interviewed.

The sample included ethnic African migrants from Sub-Saharan African 
countries living in WA. Sub-Saharan countries are African nations south of the Sahara Desert. Convenience sampling was used to recruit volunteer participants, which enabled us to include diverse participants from a wide range of African countries. Selection criteria were as follows: ethnic adult African migrants (aged 18 years or above) of either gender, from Sub-Saharan African countries who had become permanent residents or citizens of Australia. Temporary visa holders were excluded because they may not have been allowed to stay in Australia.

The recruitment process involved the following. Flyers outlining the purpose of the study were displayed in public places around the Perth metropolitan area, appealing to interested individuals to contact the first author. Participants were also recruited by word-of-mouth through the first author's social networks. The length of time for participants in Australia was between one and 17 years. All participants had gained Australian citizenship or had permanent resident status at the time of the interviews.

The in-depth interviews allowed participants to express their experiences and feelings pertinent to their personal circumstances. Participants who were interviewed were asked about barriers hindering their successful resettlement in Australia and how they coped with difficulty situations. The interviews took approximately 45 to 60 minutes to complete. The interview questions about barriers to resettlement and the coping strategies are as follows:

- Barriers to resettlement: participants were asked to name any barriers hindering their successful resettlement in Australia, and to indicate the most challenging situations they had encountered since coming to Australia. If they had children, they were also asked to indicate any particular concerns for them.

- Coping strategies: participants were also asked to describe how they coped with the most challenging situations, and to explain how their families and/ or friends had helped them deal with these situations. Additionally, they were asked to specify whether they belonged to a community group, church/mosque or other support organisation, and, if so, what role these organisations had played in.

The interviews were fully transcribed and analysed following an Interpretative Phenomenological Analysis, using thematic content analysis. The data was coded using open coding as each transcript was read and reread to ascertain the meaning of its content. Similarities and differences in the data were identified and colour coded, and words capturing similar ideas were reduced in each line: the main categories were created and various themes identified. Finally, a number of major themes and subthemes emerged from the data. 


\section{Findings}

In this section we report the major themes related to causes of stresses and coping strategies and deriving from the interviews.

\section{Causes of stress}

\section{Separation and loss}

Participants who were mothers reported that they experienced increased responsibilities after migrating to Australia, which they found very stressful. Many of the interviewees stated that they were stressed because they no longer had access to extended family members who could help them care for their children. Participant 14 expressed eloquently the sense of loss and how it affected her. Participant 14's account was not isolated by shared by a number of the migrants. She said

My biggest problem is not being able to cope well with the absence of my family who were a huge source of support, emotionally and practically with issues such as childcare. Having the children by myself hundred per cent of the time and having to work is draining. I went and sat down and convinced myself, 'I have to look after my children'.

The African migrants spoke freely about the difficult situation they had encountered upon arriving in Australia. Participants experienced multiple losses, including the loss of their culture, food, family, friend and social networks. Participant 11 stated that:

Oh, heaps [of losses] —your family and the support network. It's not there-it takes a lot to build that up.

The missing of the family and other relative shows the importance of the extended family network in Africa, where most cultures are largely collectivistic. The sense of loss was felt in human terms with the missing of the family and childhood friends. However, other cultural artifacts and constructs added to the loss expressed by the participants. For instance, a participant explained that her sense of loss was exacerbated by:

The lack of food from back home here in Australia. You have to go a long way to find something to eat which is typically and culturally African. That depresses me even more. 


\section{Culture shock}

Participants reported experiencing culture shock when they initially arrived in Australia. Most aspects of social and cultural life were significantly different from practices in the participants' homelands. These differences ranged from the dressing style for women to the way people interact and communicate. The experience very psychologically distressing. As another participant 14 said:

The culture shock was a big thing for me. I don't think that I ever saw young girls exposing their bellies; and particularly one thing I remember very well, the motherspregnant and they were exposing their bellies; they ... go around with very short skirts and shorts. I never saw that in my country. Okay the fancy styles, yes those ones are there in the cities back in Africa, but not the almost walking naked, no. (Participant 16)

Though the participants were generally happy to have made the move to Australia, many were concerned that their sense of loss did not end with their losing the homeland. They now feared that they have lost their children - both new comers and those born in exile - to Australian culture. Despite trying hard to teach them African language and culture at home, some African migrant families felt that it was a game lost. They had concerns related to acculturation and were worried about their children being drawn into drug or alcohol abuse. The migrant parents were concerned about the rapid adoption of the new culture by their children. One of those who were concerned stated:

With my big daughters, from their talking, I realise that they are drifting into these [cultures]... and I try to bring them back. I tell them, 'remember where we come from-Africa-with our culture. I don't want you to get lost into the things you see here. (Participant 25)

Another migrant mother who was anxious about the rapid westernisation of her children was firmer in her approach to drawing them out of a popular culture that she saw as corrupting the values she was trying to get her daughters to internalise. The mother participant hinted some of the stiff warning she had for her daughters:

You are not going to walk naked as [wearing short shirts or shorts] ... in front of me.

owever, some African migrants had no concerns about their children because their children had adjusted well and had made the transition to resettlement easier for their families. The unconcerned migrants expected their children to grow up as a new generations that espouse the value of their new country. The words of one of these migrant parents summarise the main view of the non-conservative African migrants: 
I came here to live here, to be safe, to work here and to belong here. I am happy that my children have learned Australian society and values. They won't be different from anybody else.

\section{Migrants' unmet expectations about the host country}

Thirteen of the migrants had very high expectations when they arrived in Australia, which caused stress when they were faced with stressful situations. They believed that Australia was issue-free and that most of their needs could be met almost effortlessly. These participants had fled their homeland to neighbouring countries because of civil war and expected the safe haven to be a place without anxiety. These assumptions were formed while they lived in refugee camps prior to coming to Australia on a refugee status. One of these participants said:

Well, to be frank, at first I had very high expectations, but some of those expectations dropped later realizing that life in Australia is not as easy and stress-free as I imagined.

I got to know that things are not all roses-you have to struggle. (Participant 13)

\section{External and self-constructed oppression}

A key issue that the migrants faced that was independent of their own doing was racial discrimination.

This was prominent in the narratives of the migrants. 18 of them reported experiences of racial discrimination which was operating in both the wider society and in the employment market. The migrants felt that equal opportunity laws were inadequate to protect them. For example, they believed that employers circumvented these laws by providing other reasons for not employing them, leading the qualified migrants to go through a period of professional tragedy. Three participants explained their experiences of racial discrimination - which were echoed by many of the 18 migrants who reported the issue:

One thing that still sticks to mind for me is racism here-it is there, but it is subtle and many times people do not want to talk about it (Participant 29).

I have experienced open racism where people call you names or where you walk on the street and someone says 'go home' (Participant 18).

Hidden, more subtle racism, as explained by participant 29 is the most hurtful of all racism in the participants' view. Another participant expresses this with vivid words:

Ah silent racism! It's especially when you go to institutions, you get that silent treatment-turning heads and treating you like you don't exist. Though they may not say anything, you can read the disdain in some people's eyes. That's threatening, 
humiliating and unwelcoming.

However, the oppressive forces that hold the African migrants back does not reside only in the external environment in the form of racism. These forces also come from within the migrant enclaves and families in the form of domestic violence.

Two participants - (aged between 26 and 28 years) had witnessed domestic violence between their parents. But more significantly they reported that domestic violence was a big issue within African communities. The participants believed that this was a major stressor which had a significant effect on their mental health. They proposed that education about domestic violence should be provided in African communities. Surprisingly, the two participants had witnessed domestic violence between their parents; however, their mother, who was also a participant in this study, did not disclose any issue about domestic violence. This was associated with a 'code of secrecy' linked cultural values. Participant 9 stated:

I think this is quite sensitive, but domestic violence is a big issue in the African community. I don't mean just physical violence but I also mean emotional violence

... I've seen it quite a bit occur, and I think a bit more education on how it affects children because it does have a big effect on children.

Participant 10 supported this and commented on the reasons why domestic violence is hidden within the African families and migrant enclaves.

Overall, participants experienced stressors such as culture shock, multiple losses, separation issues, high expectations, parenting issues and domestic violence between their parents felt very distressed. A number of factors enabled many of the participants to deal with oppressive issues and move forward with their new lives. The next section examines the practical steps that African migrants in Australia take to cope with the issues faced in the new cultural context.

\section{Coping strategies}

\section{Family support}

Twenty participants mentioned that they were able to cope well with difficulties due to support from their families, both here in Australia and in their country of origin. Some would telephone their families in their country of origin to received the needed support. Their responses were as follows:

We always talk about [stressful] issues as a family. That's what I think has helped us all the time, from when we first arrived in this country. We talk about what has happened and then each person comes in and gives some kind of support. We [also] 
encourage family members to share their problems. (Participant 18)

Yeah ... my family is supportive-they're supportive if I have problems, and they've been behind [me]. Like, I had a problem at work and I had to stop work almost immediately-my whole family supported me and helped me to get through the issue. (Participant 26)

Surprisingly, the children have actually made my transition even easier because they are very happy to be in Australia and one reason, I think-actually, they've categorically told me-that one reason they like Australia is that there are parks nearby and they can go there to run around, to play. And also, they have their cousins here and they are very close and they really play together very well. They [also] link up with their cousins in Ghana. So when we came here and they saw their cousins and they play together, that has really made the transition easier than I thought. (Participant 6)

\section{Newly constructed social networks}

Seven participants reported that they coped well by sharing their problems with their support networks for guidance. Their friends and other support networks were from a range of places, including their home countries, the African community in Perth, workplaces and learning institutions, such as TAFE or universities. Their responses were as follows:

Oh, friends are very important because your friends are the ones who give you the moral support, your friends are the ones who listen to you when you have problems, your friends share their own stories with you and you learn from them. Your friends are the ones who help you if you need to find another job, they will give you guidance and tell you where to look. As I said before, your friends now become your family here, so they are very important in that situation. (Participant 23)

Friends they help a lot. Sometimes it's in the area of provision of certain things that might be lacking, and also connection-they can try to link you to some potential employers. For instance, I was connected to my current job by my friends and other support network. And before I got a job, I received so much help, like food and money from my friends. (Participant 24)

Eight participants spoke about their connections with other African community in Australia, and the way they used the community to socialise and for support during major events such as weddings, and Christmas and New Year celebrations. They reported that members of the African community help new migrants with their initial resettlement needs, such as providing transport and other needs. Further, they also help other African migrants who are facing difficulties in 
resolving their problems.

At the moment, I am a member of the African Community Association and also a member of specific community groups_-for example, Congolese community and also Kenyan community. If I get a problem which can cause stress, I go to see my friends from my community, express my feelings to them [and] they find ways of assisting me. I also help other African migrants with no jobs by employing them in my hair salon business. (Participant 11)

I come from a community where people live in a community, so what troubles me, troubles them as well, and they'll be there to offer me encouragement and support. (Participant 29)

\section{The power of faith}

Two-thirds of the participants (21 out of 30) stated that they had faith and belonged to different faith communities. There is a convergent acknowledgement that faith helped them through the difficulties of migration and dislocation. Many of the African migrants believed that faith provided psychological healing, spiritual renewal and fostered opportunities for them. Some participants summarised this heavenly salvation in the following terms:

I believe very much that every human being needs some spiritual strength from God. I believe there's a God who helps his creation (Participant 15)

A lot of problems that we encounter as human beings, only God sometimes can best help us. (Participant 24)

The heavenly intervention was felt by many participants who believed that it is faith that helped them find the way to Australia. It is faith again who placed relevant people on their resettlement paths to provide comfort, reassurance and practical help. As a participant claimed:

I belong to the Seventh Day Adventists church back home. When I arrived in Australia, the Lord [God] showed me where to find them. I found the church and I started attending the church. That was a blessing in disguise. (Participant 30)

The church played a big role [in my resettlement in Australia]. After I came here, a few weeks later, I found the church and I started attending the church. The additional support from church, made settling a lot easier. (Participant 20)

This account was corroborated by six other participants. Divine intervention was not limited to guiding the participants to find a church, but it was, in their eyes, 
visible in all walks of life, from finding other Africans and local communities that would embrace them to finding jobs, having children and remaining healthy, etc. A participant linked his finding his first job to divine intervention; he explained:

After I came here, I wanted a job so that I could start to make sense of this place. But many weeks and months later, I was still without a job. Something told me 'you must pray'. I straight away knew that God was speaking to me. I knelt and prayed for three days. The next Sunday after the service, a brother in Christ called me and asked if I was looking for a job. I said yes and he invited me to come to his office the next week. When I turned up he showed me the job I was going to do. People might not believe but I think only the divine can do this (Participant3).

Participant 4 who also 'experienced the hand of the Lord' recounted her heavenly gift:

A year exactly after I arrived here, I had my baby. That was a big gift from Him [God].

Because it changed my life. I went from a sad depressed person to a happy mother.

I had a sense of purpose.

Participant 4 also thought that the charity workers who looked after her and her child, providing assistance with clothes, gifts and friendly visits were led by the Spirit. This account was widespread among the participants.

Overall, the data shows that most participants used coping strategies, such as seeking support from family, friends, African communities, and finding employment. However, the most significant strategy was reliance on faith for guidance and intervention to deal with resettlement difficulties, e.g. stress, depression, homesickness unemployment, etc.

\section{Discussion}

\section{Resettlement stressors}

The findings indicate that all participants experienced multiple losses, including the loss of their culture, food, family, friend and social networks. These findings are supported by Ogunsiji et al.'s (2012) study in Sydney [Australia] which identified multiple losses as a major source of stress for African migrants because they perceived they had lost everything they had achieved in their homeland, and described their loss as stating again. This finding aligns with most previous studies of effect of dislocation on migrants (see Scharp, Paxman $\&$ Thomas, 2015; HackPolay, 2012; Lin, 1986; Fisher et al., 1984).

The participants in our study, regardless of their migration status, identified 
culture shock as a cause of their stress when they initially arrived in Australia. Some experienced culture shock associated with the style of dress for women in Australia. This is consistent with the findings of another study who linked culture shock to adaptation or adjustment (Dunbar, 1993). This is also consistent with the findings of Casimiro, Hancock \& Northcote (2007) about Muslim refugee women in Australia. The seminal study of Berry (2005) also purported that culture shock represents a major resettlement stressor because of the attempt to merge two cultures together. The findings show that participants had concerns associated with cultural issues for themselves and their children. Adjusting to a new culture and environment is significant in migrant resettlement, particularly for those originating from culturally distant backgrounds (Hemmasi \& Downes, 2013; Hinsliff, 2006). Equally, during the process of acculturation, non-dominant groups in the society may experience a great deal of stress when trying to adjust to their new life in their host country (Brand et al., 2014).

The findings indicate that the resettlement stress that African migrants $(n=18)$ experience is compounded by their experience of racial discrimination operating in employment market and felt that equal opportunity laws were inadequate to protect them. Likewise, one-third of Sudanese refugees in Australia experienced discrimination (Murray, 2010). In addition, Fozdar and Torezani (2008) found high levels of perceived discrimination among refugees.

While several of the findings reported above may be similar to a variety of migrants and locations, our study revealed that unfulfilled expectations were a significant source of resettlement stress for African migrants. Many participants $(n=13)$ reported that they had very high expectations when they arrived in Australia. Such findings are limitedly reported in the literature. Such limited reports about the link between expectation of the new country and stress are by Cox et al. (1999) and Stein (1986). They postulated that most refugees expect to recover from their lost status when they arrive in the host country. Additionally, a significant finding in our study indicate that adult children who were living with their migrants parents reported that witnessing domestic violence between their parents, and they also claimed that it was very common within African communities. Domestic violence among migrants is also under-reported in the academic literature. Only a major study in the US considered the issue and found that the role reversal is a major factor affecting relationships within the families of African migrants and can result in family violence, breakdown and divorce (Heger Boyle and Ali, 2010). As a consequence, children and adolescents witnessing domestic violence are at increased risk of experiencing emotional distress (Holt et al., 2008).

\section{Coping strategies}

The literature identifies many strategies for copying with resettlement stress 
among migrants, e.g. community involvement, obsessive attachment to particular items, obsessive thought about home, medicalization, etc. (Hack-Polay, 2012;....). Our participants too deployed many of these strategies signalled in the literature. However, our research unveiled and reinforced three significant strategies employed by African migrants in Australia that commend further reflection. These are: family by alliance, ethnic networks and faith.

Unsurprisingly, the majority of the African migrants interviewed relied on friends and family members to cope with stress. Some would telephone their families in Africa to find the much-needed support. This is consistent with another study in the US which found that Ghanaian migrants cope by maintaining ties to their homeland through keeping in regular contact with their families (Owusu, 2003). Similarly, another study in Australia reported that the coping strategies used by Sudanese refugees include seeking support from extended family members and friends (Schweitzer et al, 2007). However, a striking finding of our study is the nature of family that some participants referred to. Some participants called brothers or sis, or uncles and aunts people from their cultural or of the same nationality. This is an extrapolation of the notion of family in the African migrant milieu. This emphasizes the importance of utilizing of culture (collectivism in the case of the African migrants) as a tool for successful resettlement in Australia. By calling the 'strangers' from their national origin relatives - what we have termed 'family by alliance' - they build trust and extend their newly developed close networks.

Our study also shows that participants engaged in African community activities and used other support networks who show cultural proximity to socialize and to help them solve stressful situations. A study by McMichael and Manderson (2004) established that African refugees needed to rely on support networks from their various communities, as this gave them a sense of belonging to a recognizable and supporting collectivity and provided them the means to deal with their immediate needs. Also, networks act as an assurance during the resettlement process of migrants (Coleman, 2006).

The findings also indicate that that more than two-thirds of participants $(n=21)$ believed in the divine and belonged to different faith communities, as they found this to be helpful in making the resettlement process easier. A previous study also found that prayer and belief in the divine are effective coping strategies for dealing with past trauma, among the Sudanese refugees in Australia (Khawaja et al., 2008). Faith helped the migrants to be tolerant to critical social issues in exile, e.g. unemployment, racism, anxiety, etc. Since they believed that a divine force brought them to safety in Australia, He would be gracious in helping them to have children, find jobs, health and hope, etc. Having faith led many of the African migrants to find 'peace', knowing that the difficulties they may be facing were only temporary. In a similar fashion, the migrants will resign to leaving everything to heaven, even when they felt they have been badly treated by some sections of the population or by the system. Religious fervor, thus, increased among the migrants, 
particularly in the early months or few years following relocation to Australia. The complexity associated with such heavy reliance on the 'divine' is the development of a disempowering laissez-faire approach whereby some migrants would sit back and await opportunities from heaven as opposed to deriving from human hard work.

The current study builds on Khawaja's study by examining the major stressors affecting African migrants and how they cope with stress in Australian. Our study indicates that most participants experienced similar stressors and developed coping strategies.

\section{Conclusion}

The present study indicate that African migrants regardless of whether involuntary or voluntary migrants experienced similar stressors including; multiple losses, culture shock, separation issues, parenting issues and racial discrimination, whereas, involuntary migrants reported high expectations when they arrived in Australia. Additionally, similar coping strategies were used by both involuntary and voluntary African migrants which included use of support from family members, friends, African communities, and belonging to faith communities as coping strategies. While religious organisations are instrumental in the integration of migrants and their emotional wellbeing, they ought to ensure that the migrants who approach them do not become solely dependent on such organisations but they are referred to other appropriate services for needs that the Church cannot meet immediately, e.g. job findings, multicultural networking, integration and citizenship learning, professional counselling, physical health services, etc. At the same time, given the importance of faith and religious services to the African migrants, general service providers need to be more sensitive in that sense and integrate a degree of pastoral care in their provision, e.g. invite the services of religious leaders, when appropriate. Such integrated service provision, in the context of Australia and other multicultural societies such the UK, the United States or France, etc. could yield more success in citizenship preparation and community cohesion.

Subsequently, though only a few participants who were adult children living with their parents reported that they witnessed domestic violence between their parents, they stated that domestic violence was a big issue within African communities. This finding has particular resonance for social work practice. It raises issues of child protection that appear to be limited with regards to intervention in migrant families. There is a particular educational role for social services and social workers within African migrant families given the cultural differences and the varying interpretation of child protection issues across cultures. Further social work practice research is needed to investigate the problem of domestic violence and child protection in migrant communities to provide policy and intervention framework. 
Our study appear to be the first within Australia to examine the major stressors impacting on African migrants and how they cope with resettlement stress; it provides baseline data. The main limitations of our research centre on the fact that we have not been able to systematically segregate the participants into voluntary vs. forced migrants as the experiences of the two categories could have some variations. It would be useful to conduct further research to gain greater understanding of stressors and coping strategies used by these groups of migrants. In the same perspective, it would be important for future research to consider a larger sample in order to attempt to identify trends.

\section{References}

Abur W., \& Spaaij, R. (2016) Settlement and employment experiences of South Sudanese people from refugee backgrounds in Melbourne, Australia. Australasian Review of African Studies, 37, 2, 107

Ager, A., \& Strang, A. (2008) Understanding integration: A conceptual framework. Journal of Refugee Studies, 21, 2, 166-191. doi: 10.1093/jrs/fen016

Ahmed, B. A. (2006) Report of the African-Australian community's initiative workshop on issues affecting the resettlement of Africans. African Think Tank Inc

Baird, M. B. (2012) Well-Being in Refugee Women Experiencing Cultural Transition', Advances in Nursing Science, 35, 3, 249-26 210.1097/ANS.1090b1013e31826260c31826260

Berry, J. (2012) Acculturation: Living successfully in two cultures', International journal of intercultural relations, 29, 6, 697-712

Berry, J. W. (1970) Marginality, stress and ethnic identification in an acculturated Aboriginal community, Journal of Cross-Cultural Psychology, 1, 239-252

Brand, R., Loh, J. M., \& A.Guilfoyle, A. (2014) Young African Female Refugees' Sense of Acculturation and Community Connection in Western Australia', Office Bearers of the APS College Of Community Psychologists, 26, 2)

Casimiro, S., Hancock, P. and Northcote, J. (2007) Isolation and Insecurity: Resettlement Issues Among Muslim Refugee Women in Perth, Western Australia, Australian Journal of Social Issues Vol.42 Nol, pp.55-69

Colic-Peisker, V. (2009) Visibility, settlement success and life satisfaction in three refugee communities in Australia', Ethnicities, 9, 2, 175-199

Cox, D., Cooper, B., \& Adepoju, M. (1999) The settlement of black Africans in Australia: Department of Social Work and Social Policy, La Trobe University

Dunbar, E. (1993) Adjustment and satisfaction of expatriate US personnel', International Journal of Intercultural Relations, 16, 1, 1-16

Fozdar, F., \& Torezani, S. (2008) Discrimination and well-being: Perceptions of refugees in Western Australia', International Migration Review, 42, 1, 30-63

Goodman, J. H. (2004) Coping with trauma and hardship among unaccompanied 
refugee youths from Sudan. Qualitative Health Research, 14, 9, 1177-1196. doi: $10.1177 / 1049732304265923$

Hack-Polay, D. (2008) Migrant integration: case for a necessary shift of paradigm, Journal Identity and Migration Studies, 2, 1)

Hack-Polay, D. (2016) Reframing migrant integration: reconceptualising citizenship and nationhood in Europe, Book Guild, Brighton

Hack-Polay, D. (2012) When home isn't home-A study of homesickness and coping strategies among migrant workers and expatriates. International Journal of Psychological Studies, 4, 3, 62-72. doi:10.5539

Hack-Polay, D. (2010) Dating and Marriage among Britain's African

Refugees: A Means of Socialisation?, Finnish Journal of Ethnicity and Migration, 5, 1) 29-37

Halcón, L. L., Robertson, C. L., Savik, K., Johnson, D. R., Spring, M. A., Butcher, J. N. \& Jaranson, J. M. (2004) Trauma and coping in Somali and Oromo refugee youth. Journal of Adolescent Health, 35, 1, 17-25

Heger Boyle, E., Ali, A. (2010) Culture, structure, and the refugee experience in Somali immigrant family transformation, International Migration, 48, 1, 47-79

Hinsliff, J. (2006) Integration or Exclusion. The Resettlement Experiences of Refugees in Australia. Retrieved November, 24, 2018

Hemmasi, M. \& Downes, M. (2013) 'Cultural distance and expatriate adjustment revisited', Journal of Global Mobility: The Home of Expatriate Management Research, Vol. 1 Issue: 1, pp.72-91, https://doi.org/10.1108/JGM-09-2012-0010

Holt, S., Buckley, H., \& Whelan, S. (2008) The impact of exposure to domestic violence on children and young people: A review of the literature. Child abuse \& neglect, 32, 8, 797-810

Hancock, P. (2017) Recent African refugees to Australia: Analysis of current refugee services, a case study from Western Australia. International Journal of Psychological Studies, 1, 2,10

Khawaja, N. G., White, K. M., Schweitzer, R. \& Greenslade, J. (2008) Difficulties and coping strategies of Sudanese refugees: A qualitative approach. Transcultural Psychiatry, 45, 3, 489-512. doi: 10.1177/1363461508094678

Kobasa, S. C. (1979) Stressful life events, personality, and health: An inquiry into hardiness, Journal of Personality and Social Psychology, 37, 1-11

Kuyini, A. B., \& Kivunja, C. (2018) African refugee spouses' experience of resettlement in regional Australia: Disempowering and empowering narratives. International Social Work, 0020872818808352

Maneze, D. et al. (2014) Acculturative stress in Filipino migrants with functional English: implications for health promotion, International Journal of Culture and Mental Health, 7, 4, 357-369, DOI:10.1080/17542863.2013.812131

McMichael, C. \& Manderson, L. (2004) Somali women and well-being: Social networks and social capital among immigrant women in Australia. Human Organization, 63, 1, 88-99

Muli, C., Pittaway, E. \& Shteir, S. (2009) 'I have a voice-hear me!' Findings of an Australian study examining the resettlement and integration experience of refugees and migrants 
from the horn of Africa in Australia. Refuge, 26, 133

Murray, K. E. (2010) Sudanese perspectives on resettlement in Australia. Journal of Pacific Rim Psychology, 4, 1, 30-43. doi: 10.1375/prp.4.1.30

Ogunsiji, O., Wilkes, L., Jackson, D. \& Peters, K. (2012) Beginning again: West African women's experiences of being migrants in Australia. Journal of Transcultural Nursing, 23, 3, 279-286

Omar, A. A. (2003) The resettlement experiences of Somalian refugees in Western Australia. (Master's dissertation) Curtin University of Technology

Owusu, T. (2003) Transnationalism among African immigrants in North America: The case of Ghanaians in Canada. Journal of International Migration and Integration / Revue de l'integration et de la migration internationale, 4, 3, 395-413. doi: 10.1007/s12134-0031027-x

Peisker, V. C., \& Tilbury, F. (2003) 'Active' and 'passive' resettlement: The influence of support services and refugees' own resources on resettlement style. International Migration, 41, 5, 61-91. doi: 10.1111/j.0020-7985.2003.00261.x

Phinney, J. S., Horenczyk, G., Liebkind, K. \& Vedder, P. (2001) Ethnic identity, immigration, and well-being: An interactional perspective. Journal of Social Issues, 57, 3, 493-510

Savic, M., A. Chur Hansen, A., Mahmood, M. A., Moore, V. (2013) Separation from family and its impact on the mental health of Sudanese refugees in Australia: A qualitative study. Australian and New Zealand Journal of Public Health 37, 4, 383-388

Scharp, K.M., Paxman, C.G. and Thomas, L.J. (2015) 'I Want to Go Home': Homesickness Experiences and Social-Support-Seeking Practices', Environment and Behavior pp. 1-23

Smart, J. F. and Smart D. W. (1995) Acculturative Stress: The Experience of the Hispanic Immigrant, The Counselling Psychjologist 2, 1, 25-42, https://doi. org/10.1177/0011000095231003

Schweitzer, R., Greenslade, J., \& Kagee, A. (2007) Coping and resilience in refugees from the Sudan: A narrative account. The Australian and New Zealand Journal of Psychiatry, 41, 3, 282-288. doi: 10.1080/00048670601172780

Smith, A. (2004) Reading against the Postcolonial Grain: Migrancy and Exile in the Short Stories of Kanchana Ugbabe', Research in African Literatures, 35, 3, 62-75. doi:10.1353/ ral.2004.0075

Stein, B.N. (1986) The experience of being a refugee: Insights from the research literature', Refugee mental health in resettlement countries, 5-23

Taylor, R., Forsythe-Brown, I., Taylor, H. \& Chatters, L. (2013) Patterns of emotional social support and negative interactions among African American and Black Caribbean extended families. Journal of African American Studies, 18, 2, 147-163

Ward, C. H. (2000) Migration, metamorphosis and the residual link: resources of British women to re-invent themselves. (PhD), Murdoch University, Perth, Western Australia. Retrieved from http://wwwlib.murdoch.edu.au/adt/browse/view/adt-MU20070905.85058

Zhong, B-L. et al. (2016) Acculturative Stress of Chinese Rural-To-Urban Migrant Workers: A Qualitative Study, PLOS One, June 14, 1-15, DOI:10.1371/journal.pone.0157530 